\title{
MEASURING COLLABORATION PERFORMANCE IN VIRTUAL ORGANIZATIONS
}

\author{
Ingo Westphal \\ Bremen Institute of Industrial Engineering and Applied Work Science \\ win@biba.uni-bremen.de \\ Klaus-Dieter Thoben \\ Bremen Institute of Industrial Engineering and Applied Work Science \\ tho@biba.uni-bremen.de \\ Marcus Seifert \\ Bremen Institute of Industrial Engineering and Applied Work Science \\ sf@biba.uni-bremen.de \\ GERMANY
}

\begin{abstract}
Management activities need an appropriate information basis. This applies also to the management of Virtual Organizations (VO). A potential source for this information is Performance Measurement. But traditional Performance Measurement (PM) methodologies and indicators are designed to assess the performance of single companies or static networks. Specific challenges and requirements of VOs are not addressed in an appropriate way. An essential aspect is for instance the collaboration performance, which has in many VOs a vital impact on the success. The objective of this paper is to provide an approach for addressing collaboration performance in the performance measurement of a VO. Therefore the main perspectives of collaboration performance and examples for potential indicators are described.
\end{abstract}

\section{INTRODUCTION}

Collaboration is today an established option to deal with the increase in product and service complexity, dynamic of changes, requirements upon responsiveness and still high quality demands. It helps to overcome the limitations of a single enterprise, especially of small and medium sized enterprises, regarding competences, capacities and financial resources. According to our understanding collaboration creates an environment in which enterprises and human actors temporarily or permanently can merge their processes for performing joint business in non-hierarchic way. A special type of collaboration is represented by Virtual Organizations (VO). Kürümlüoglu et al. define a $\mathrm{VO}$ as a set of co-operating (legally) independent organizations, which to outside world provide a set of services as if they were one organization, supported by a computer network [Kürümlüoglu et al. 2005].

However, collaboration is no general guarantee for success. Research has shown that many collaborative organisations were not able to accomplish the set goals [Bamford et al. 2004; Bullinger et al. 2003; Dürmüller 2002]. Deficits in the management of the collaboration constitute one category of the identified reasons for failure.

An essential prerequisite for an effective management is a sound information basis. Performance Measurement (PM) is an important source for this information.

Westphal, I., Thoben, K.-D., Scifert, M., 2007, in IFIP International Federation for Information Processing, Volume 243, Establishing the Foundation of Collaborative Networks; eds. Camarinha-Matos, L., Afsarmancsh, H., Novais, P., Analide, C.; (Boston: Springer), pp. 33-42. 
We understand PM as the systematic approach to plan and conduct the collection and monitoring of data regarding the accomplishment of defined tasks and corresponding objectives [ECOLEAD 2005]. Several research activities dealt with Performance Measurement and various approaches like EFQM, Balanced Scorecard, Six Sigma or the Performance Prism have been developed. Overviews about PM research are given e.g. by Sandt [2005] or by Graser et al. [2005]. So what could be the reasons that existing PM approaches do not provide a sufficient information basis for the management of collaborations? One potential reason is that they are difficult to apply in a non-hierarchic network of independent partners. A second potential reason could be that the existing approaches do not cover all aspects needed for the management of the collaboration.

The need for an extension respectively customisation of PM to the specific requirements of a network was already identified e.g. by Gunasekaran [2001], Leseure [2001] or Hieber [2002]. However this research work was focused on static networks like supply chains with a more hierarchic character and even for supply chains there are still unsolved challenges regarding PM [MacBeth 2005]. The requirements of dynamic VOs are not addressed in the exiting approaches. In particular the consideration of interaction between independent VO members in merged processes is a specific challenge of PM in Virtual Organizations (VOPM).

This leads to the other potential reason for a lack of management information: The insufficient application of PM. PM in a network is also a collaborative process. If there is resistance against a common PM this is a symptom that shows that the planned PM activities do not match the actual status of collaboration capabilities and willingness.

So the objective of this paper is to widen available PM approaches to meet the specific requirement of VO management in a better way. It will focus on the aspect of collaboration performance that is one of the essential differences between VOs and single companies as well as static hierarchic networks.

A defined structure of the main aspects of collaboration performance in VOs supports a better understanding of this performance perspective and the related communication. This is not only beneficial for managing the operation phase of a VO but also for the consortium formation in the creation phase. So the considerations can contribute to current research activities regarding VOs and other collaborative network organisations.

\section{PM REGADING INTERACTIONS BETWEEN COMPANIES}

As already stated in the introduction, the vast majority of research work upon Performance Measurement is focussing on perspectives like cost, quantities, time, and quality. These perspectives are used to assess the accomplishment of defined objectives. To obtain information about potential future results new perspectives were added mainly in the early 1990s. A well known and established example is the Balanced Scorecard of Kaplan and Norton [Kaplan et al. 1992] that adds the perspectives customer, processes, learning/growth to the traditional financial perspective. In addition some approaches consider also intangible aspects like human capital, strength of brands or established customer relationships that are relevant for the company's value that moved more and more in the centre of attention in the middle of 1990s. Examples are the Skandia Navigator [Skandia 2007] developed decisively by Edvinsson in 1993, the Intangible Assets Monitor of 
Sveiby in 1996 [www.sveiby.com] or the Intellectual Capital Monitor of Stewart [1999]. These examples have shown that also "soft-facts" can be assessed in a performance measurement based on values.

However there was still a gap regarding the performance of interaction between partners. Approaches that intended to fill this gap are looking at this type of performance mainly from two viewpoints: Either they tend to assess the actual interaction between partners or the general capability of a company to cooperate, which is important for self-assessment and partner selection.

Works that are focussed on the assessment and control of interaction are for example Beamon [1999], Leseure [2001], Gunasekaran et al. [2001], Supply Chain Operations Reference Model (SCOR) [www.supply-chain.org], Hieber [2002], Schweier [2004], Sivadasan et al [2002] or Simatupang and Sridharan [2004]. Performance perspectives suggested by these approaches are for instance equity, flexibility, reliability, responsiveness, partnership, collaboration efficiency, generic cooperation performance, absorption of complexity in collaboration, information sharing, decision synchronisation or incentive alignment (sharing of risks, costs and benefits).

More recent works like from Höbig [2002] or Seifert [2006] are looking at the performance of interactions between partners from the viewpoint of assessing a company's capability and preparedness for cooperation.

Höbig analysed in his work the general cooperation capabilities of production enterprises. The main criteria are: Communication capability, peparedness for future developments, adaptability, stability, reliability, and customer orientation. For each of these criteria, generic high-level indicators are defined.

Seifert analyses in his approach different combinations of partners to accomplish a production task. The assessment of the different consortiums is based on the values the potential partners have achieved for defined performance indicators. As the approach is build upon the SCOR model and the corresponding indicators it covers also some aspects of interactions between partners.

Regarding the practical application of the approaches cited above for a particular VO there are some weaknesses respectively shortcomings. At first, there is a lack of clear descriptions what is included in the performance perspective of interaction. In addition the approaches have some gaps with regard to the complete set of relevant perspectives of performance in the interaction of network partners that goes beyond a very generic level and is not just describing interactions.

Thus the following chapter aims at a suitable definition and an overall picture of the performance perspectives that cover the interaction of partners in a VO.

\section{MEASURING COLLABORATION PERFORMANCE IN VO}

Main subjects of this chapter is to clarify the term of collaboration performance in VOs and the development of an approach to structure the different sub-perspectives of collaboration performance in VOs.

The first step is to describe performance measurement in VOs (VOPM). Following the interactions of VO members are characterised and a definition for collaboration performance in VOs is provided. The characteristics and the definition are used to structure the potential perspectives of collaboration performance. The perspectives are obtained from literature and the practical experiences of existing networks. 


\subsection{VO Performance Measurement - VOPM}

Performance Measurement is an essential task of VO Management. It supports the accomplishment of defined objectives by clarifying them and providing transparency about the degree of accomplishment.

The following graphic should give an overview over the different types of performance that has to be measured by VOPM.
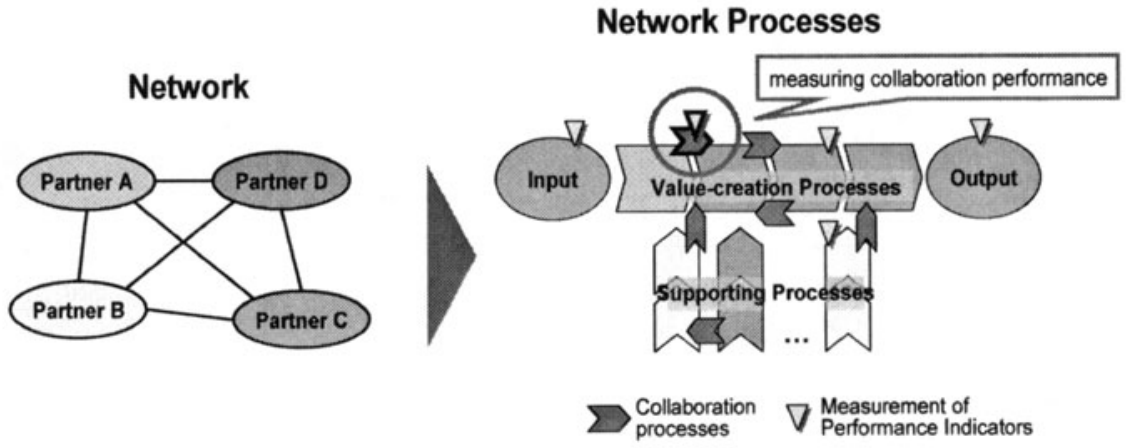

Figure 1 - Types of measurement points

The different types are:

1. Performance of the VO as a whole (output/results received by the customers and the VO's stakeholders).

2. Performance of the VO member and suppliers regarding their contributions to the value-creation process and the supporting processes (enablers).

3. Performance of VO members' collaboration ("lubrication").

While the fist two types of measured performance are generally the same as in single companies and static, hierarchical networks the third type of performance data is particularly important for the management of collaborative activities. It considers the effectiveness and efficiency of interactions between the independent network partners when they merge their processes to accomplish the common task in nonhierarchic way. We understand this as collaboration performance.

\subsection{Collaboration Performance in VOs}

The importance of collaboration performance for VO management can be explained with the aid of two plausible incidences.

Even if all VO members have the general capabilities to accomplish the defined task according to the defined objectives it is not guaranteed that this is practically achieved. There are effects that obstruct the full development of capabilities in the merged processes. For instance one of the partners has specific know-how to solve a certain problem but he hesitates to provide this to other companies in the network. A second example is that only low priority is given to the VO-activities in case of short capacities. Collaboration has to deal with these effects to ensure effective and efficient work in the VO. 
Another reason for the necessity of collaboration is the fact that it is almost impossible to regulate all issues and all potential situations when a VO is created. Consequently unforeseen and not regulated problems will occur during the operation phase of a VO. This gap in agreed regulation has to be filled by the VO members with new agreements and actions, in many cases under tough time constraints. Without effective collaboration this could jeopardise the overall success of the VO.

In the following paragraph the need for concrete types of collaboration performance should be derived from the main characteristics of VOs. Input for the considerations comes from literature and from practical experiences in the ECOLEAD project'.

The main characteristics are [ECOLEAD 2005]:

- Independency of partners.

- Dynamic.

- Uniqueness.

- Temporary limitation.

According to the independency of partners there is no higher authority that can take the final decision and force VO members into doing something. Only concrete contractual agreements can be demanded from the partners. So it is essential to reach common decisions and agreements. This requires the willingness to do so, the ability to achieve compromises, and competences in problem solving. To support compromises and problem solving the partners have to communicate effectively.

Another characteristic of VO that occurs in many cases is the dynamic in VO creation process and sometimes even during the operation phase. This leads usually to restrictions regarding detailed formal agreements. Especially if the VO has to fulfil complex tasks there will be many issues that remain un-discussed and unregulated. On the one hand this requires common decisions and agreements like described above. On the other hand there is necessity for flexibility to react on dynamic changes, ability to compensate problems, responsiveness and for reliability that avoids additional changes caused by VO members.

VOs are unique organisations. Usually they will not come together in the same constellation when they dissolved. Thus they can not be build on experiences from the past. When the VO is created many things are new and uncertain. To handle this uncertainty the partners have to be collaborative in terms of compromises, conflict solving, flexibility, and reliability. Furthermore it is necessary that the partners take the initiative to advance the work and to share information as they can not rely on well proven process patterns.

Finally it has to be considered that a VO has a temporary limitation. This influences the effort that is acceptable for preparing the VO during the creation phase. It has to be ensured that there is an amortisation of this effort before the VO dissolves. This leads again to incomplete agreements and regulations that require corresponding collaboration performance. The temporary limitation requires also initiatives of the VO members to make the best use of the limited time.

\footnotetext{
1 ECOLEAD is a rescarch project with more than 20 international partners funded by the European Commission. The consortium itsclf can be regarded as VO. In addition there are project partncrs that represent different network organisations from various industrics.
} 
One conclusion that can be drawn from the considerations above is that collaboration performance can be divided in a pro-active and a re-active part. Proactive collaboration aims at enhancement in the accomplishment of objectives. This can also be reached by active avoidance of problems and critical situations. In contrast, re-active collaboration tries to handle already occurred problems and critical situations. Initiating activities and information sharing are examples for proactive collaboration while flexibility and responsiveness belong to the category of re-active collaboration.

\subsection{Integration of Collaboration Performance in VOPM}

To obtain corresponding data for the management of the VO the aspect of collaboration performance has to be integrated into the VO Performance Measurement (VOPM). In the introduction it was shown that several PM approaches are available. The Balanced Scorecard (BSC) is an established and well known approach that provides the opportunity to be extended by performance perspectives that are relevant for specific applications. Moreover the BSC approach analysis the relationships between indicators, e.g. how quality aspects influence the customer satisfaction and future profit. This gives the opportunity clarify the influence of collaboration performance on the other perspectives. Therefore the BSC approach is chosen to be extended by the aspect of collaboration performance.

The following graphic gives an overview over the integration of the collaboration perspective and its sub-perspectives in the initial BSC. (The learning and growth perspective and the sub-perspective capital are in most cases less relevant for VOs as they have usually no own capital and their lifetime is limited.)

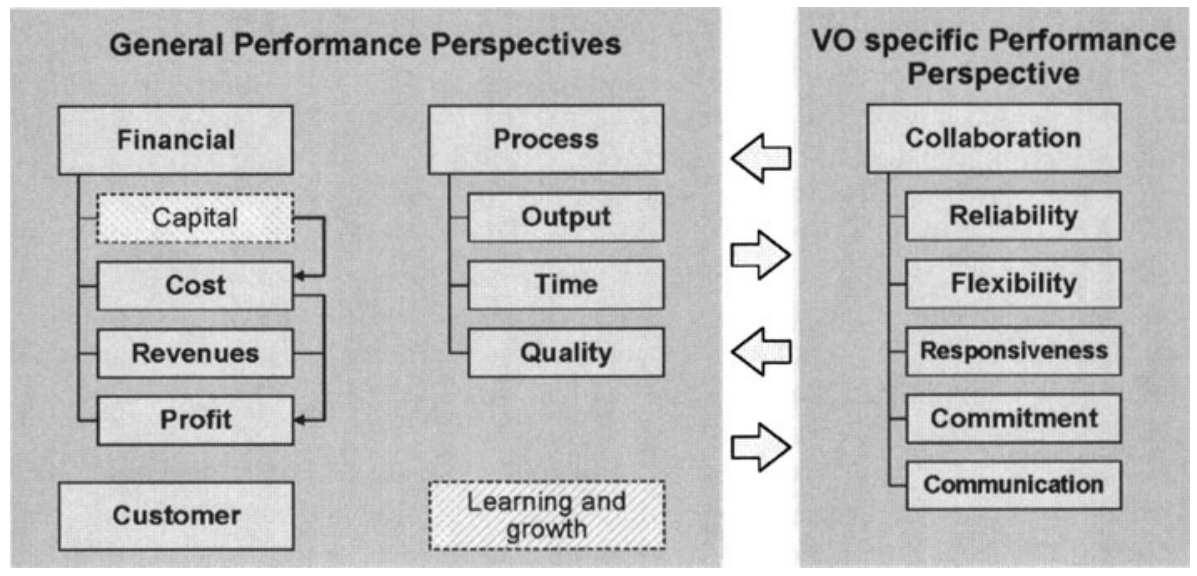

Figure 2 - Performance perspectives in VOPM

As depicted in the graphic the collaboration performance is closely connected to the other performance perspectives. On the one hand, some performance indicators can be assigned to the general perspectives as well as to the collaboration performance perspective, e.g. on-time delivery can be used for the time perspective and for the reliability perspective. On the other hand, collaboration can support the 
performance regarding the general perspective. For instance, a good responsiveness of VO members could reduce cycle times and improve on-time delivery.

The detailed description of all sub-perspectives of collaboration would go far beyond this paper. Therefore description is focused on the perspective of commitment. Reliability, flexibility, responsiveness and communication are already discussed in other approaches, e.g. SCOR or Höbig [2002]. Although this was done with another intention than measuring collaboration performance and the considerations need some extension (e.g. the aspect of confidentiality in the perspective of reliability) a general notion about these perspectives is given. In contrast the perspective of commitment is a specific core element of collaboration performance and needs some more explanation.

The perspective of commitment is introduced to summarise aspects of collaboration performance that are strongly related to the attitude towards the VO and the interaction with other VO members. It considers contributions to the VO that are not formally defined but come from the motivation of partners.

At first sight, commitment seems to be a "soft" aspect of collaboration performance that is difficult to measure. However, if commitment is divided into further sub-perspectives its meaning becomes clearer and potential performance indicators become perceptible. The graphic below presents sub-perspectives of commitment.

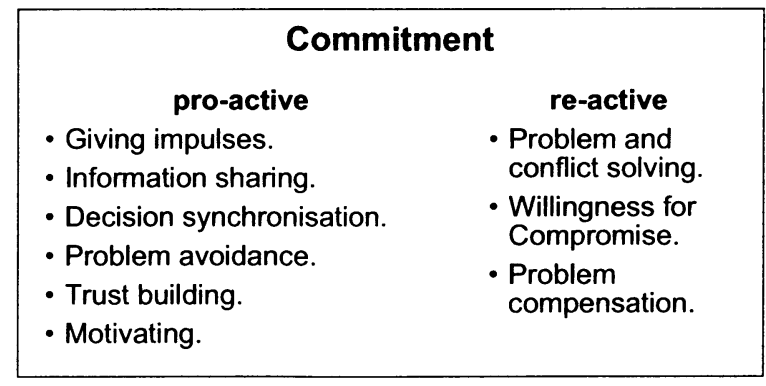

Figure 3 - Sub-perspectives of the VOPM perspective commitment

On this more concrete level of collaboration performance suitable performance indicators become more obvious. Some examples:

- Number of problems in a defined period caused by late or missing information from partners (information sharing).

- Degree of participation in meeting or conference calls - \% of all agreed meetings, $\%$ of full-time participation (Decision synchronisation).

- Frequency of adjusting/coordinating the planning with related VO members (decision synchronisation).

- Number of problems between VO members that could not be solved between the members but need escalation to the VO management (problem/conflict solving).

- Relation between deviations from planning regarding the input and remaining deviations regarding the output - based on other performance indicators like on-time delivery (problem compensation). 
Like for other performance perspectives a VO has to decide which indicators should be applied, not least because of limited resources and time. The selection of indicators is done according to the specific conditions of a particular VO. If, for instance, the VO members know each other well and have collaborated in previous VOs the need to measure trust building will be low.

Most of the indicators for collaboration performance do not provide absolute values that are objectively comparable. Rather there is a strong dependence between the indicator value and the particular composition of VO members. For instance the openness for information sharing of partner A could be very good if he interacts with partner B but, according to bad experiences in the past, very limited in the interaction with partner D. However, these "atmospheric disturbances" are exactly what should be measured by the VOPM to enable an active management of collaboration by the $\mathrm{VO}$ management.

\section{IMPLICATIONS FOR VO MANAGEMENT}

The gap in existing performance measurement approaches regarding collaboration performance is generally filled with the developed structure of collaboration perspectives. This gives the opportunity to the VO manager to monitor the collaboration in his $\mathrm{VO}$ and to take actions if corresponding indicators show unsatisfactory results. In industrial practice this can be utilised to enhance the awareness regarding the needed commitment of each partner and to implement a early warning system that indicates frictions between partner.

The developed structure of collaboration performance can also improve the selection of partners for a VO, either by regarding performance indicator values from VOs in the past or by assessing the general capabilities regarding the different collaboration performance perspectives.

Besides the application of this structure in a VO it could also provide new ideas for other networks of interacting partners, e.g. for supply chains.

Nevertheless, the intention behind the development of the suggested structure was to provide a starting point for the assessment of collaboration performance in VO. One the one hand, this implies that the perspectives and indicators have to be further improved, e.g. according to new experiences. On the other hand, it means, that even if many indicators for the collaboration perspectives are applied it has to be regarded that they will not be able to draw a complete and objective picture of the collaboration performance. To identify an appropriate set of indicators that provide good transparency about the collaboration performance in a particular VO without causing unreasonable effort is still a challenge.

\section{CONCLUSIONS}

Existing approaches for Performance Measurement do not meet all specific requirements of VO management. In particular the aspect of collaboration performance, which is essential for the success of a VO, is not considered in a sufficient way. However, research work has already provided several components dealing with interaction between network partners. These components were taken up and joined up with the specific requirements of VOs. Necessary adaptations and 
extensions were made. The result is a general structure for the performance perspectives and sub-perspectives of collaboration performance in VO. "Commitment" was introduced as new sub-perspective of collaboration performance that completes the perspectives that were already discussed in literature. The perspective of commitment summarises aspects of collaboration performance that are mostly informal and strongly related to the attitude towards the $\mathrm{VO}$ and the interaction with other VO members.

One of the next challenges is to provide a support for the VO management to identify, which of the various indicators for collaboration performance are relevant and suitable for the particular VO.

\section{ACKNOWLEDGEMENTS}

The paper is mainly based on work performed in the project ECOLEAD (FP6-IP 506958; www.ecolead.org) funded by the European Commission within the ISTProgramme of the 6th Framework Research Programme. The authors would like to grant acknowledgements to the ECOLEAD consortium, especially to the participants of work-package 3 ("VO Management").

\section{REFERENCES}

1. Bamford, James; Ernst, David; Fubini, David G.: Wie man Weltklasse Joint Venture startet. In: Harvard Business Manager, 26th Volume, May 2004.

2. Beamon, Benita M.: Mcasuring supply chain performance. In: International Journal of Operations and Production Management, Vol. 19, No. 3, 1999.

3. Bullinger, Hans-Jörg; Kiss-Preußinger, Elkc; Spath, Dicter (cds.): Automobilentwicklung in Deutschland - wie sicher in dic Zukunft. Study of Fraunhofer IAO, PROMIND, MVI Group, Stuttgart 2003.

4. Dürmüller, Christoph: Checkliste für erfolgreiche Allianzen. In: New Management, No. 6, 2002.

5. ECLOEAD Project, Work Package 3, Deliverable 3.11, www.ecolead.org, 2005.

6. Graser, Falk; Jansson, Kim; Eschenbächer, Jens; Westphal, Ingo; Negretto, Ugo: Towards Performance Measurement in Virtual Organisations - Potentials, Needs, and Research Challenges. In: Procecdings Pro-VE 2005.

7. Gunasckaran, A.; Patel, C.; Tirtiroglu, E.: Performance measures and metrics in a supply chain cnvironment. International Journal of Operations \& Production Management, Bradford, Vol. 21, Iss. 1/2, pg. 71, 2001.

8. Hicber, Ralf: Collaborative performance measurement in logistics networks : the model, approach and assigned KPIs. In: Logistik-Management, Nürnberg, Vol. 4, No. 2, 2002.

9. Höbig, Michacl: Modellgestützte Bewertung der Kooperationsfähigkeit produzierender Unternehmen. Fortschritt-Berichte VDI Reihe 16 Nr. 140, VDI Verlag, Düsscldorf 2002.

10. Kaplan, Robert S.; Norton, David P. The Balanced Scorecard - Measures that Drive Performance, Harvard Business Revicw, January-February, 1992.

11. Kürümlüoglu M., Nøstdal R., Karvonen, I.: Base concepts. In Camarinha-Matos, L., Afsarmanesh, H., Ollus, M. (eds.), Virtual organizations. Systems and Practices, Springer-Verlag, 2005.

12. Lescure, M.; Shaw, N.; Chapman, G.: Performance measurement in organisational networks: an exploratory case study. In: International journal of business performance management. - Milton Keyncs, Genc̀ve, Vol. 3, No. 1, 2001.

13. Macbeth, D.-K. (2005) Performance Measurement in Supply Chains. Presentation of the IMS-NOW SIg Mecting in Glasgow on Fcb 24, 2005.

14. Sandt, Joachim: Performance Mcasurement - Übersicht über Forschungsentwicklung und -stand. In: Zcitschrift für Controlling \& Management, Vol. 49, No. 6, 2005. 
15. Schweier, Hendrick: Aspekte eines Controlling logistischer Netzwerke. In: Gericke, J.; Kaczmarek, M.; Neweling, S.; Schulze im Hove, A., Sonnek, A.; Stüllenberg, F.: Management von Unternehmensnetzwerken. Verlag Dr. Kovač, Hamburg, 2004.

16. Seifert, M.: Unterstützung der Konsortialbildung in Virtuellen Organisationen durch prospectives Performance Measurement, Bremen 2007.

17. Simatupang, T.M.; Sridharan, R.: A benchmarking supply chain collaboration: An empirical study. In: Benchmarking, An International Journal, Vol. 11, No. 5, 2004.

18. Sivadasan, S.; Efstathiou, J.; Frizelle, G.; Shirazi, R.; Calinescu, A.: An information-theoretic methodology for measuring the operational complexity of the supplier-customer systems. International Journal of Operations \& Production, 22, 80-102, 2002.

19. Skandia: Visualizing Intellectual Capital in Skandia. http://www.skandia.com/en/includes/documentlinks/ annualreport 1994/e9412Visualizing.pdf, accessed 15.02.2007.

20. Stewart, T.A.: Intellectual Capital: The new wealth of organizations. Currency Doubleday, London 1999. 